\title{
Serotonergic gene-to-gene interaction is associated with mood and GABA concentrations but not with pain-related cerebral processing in fibromyalgia subjects and healthy controls
}

\author{
Isabel Ellerbrock ${ }^{1,2^{*}} \mathbb{D}$, Angelica Sandström ${ }^{1,2}$, Jeanette Tour ${ }^{1,2,3}$, Silvia Fanton ${ }^{1,2}$, Diana Kadetoff ${ }^{1,2,4}$,
} Martin Schalling ${ }^{5,6}$, Karin B. Jensen ${ }^{1,2}$, Rouslan Sitnikov ${ }^{7 \dagger}$ and Eva Kosek ${ }^{1,2,8+}$

\begin{abstract}
The neurotransmitter serotonin, involved in the regulation of pain and emotion, is critically regulated by the $5-\mathrm{HT}_{1 \mathrm{~A}}$ autoreceptor and the serotonin transporter (5-HTT). Polymorphisms of these genes affect mood and endogenous pain modulation, both demonstrated to be altered in fibromyalgia subjects (FMS). Here, we tested the effects of genetic variants of the $5-\mathrm{HT}_{1 \mathrm{~A}}$ receptor (CC/G-carriers) and 5-HTT (high/intermediate/low expression) on mood, pain sensitivity, cerebral processing of evoked pain (functional MRI) and concentrations of GABA and glutamate (MR spectroscopy) in rostral anterior cingulate cortex (rACC) and thalamus in FMS and healthy controls (HC). Interactions between serotonin-relevant genes were found in affective characteristics, with genetically inferred high serotonergic signalling (5- $\mathrm{HT}_{1 \mathrm{~A}} \mathrm{CC} / 5-\mathrm{HTT}_{\text {high }}$ genotypes) being more favourable across groups. Additionally, 5- $\mathrm{HT}_{1 \mathrm{~A}} \mathrm{CC}$ homozygotes displayed higher pain thresholds than G-carriers in HC but not in FMS. Cerebral processing of evoked pressure pain differed between groups in thalamus with $\mathrm{HC}$ showing more deactivation than FMS, but was not influenced by serotonin-relevant genotypes. In thalamus, we observed a 5-HT 1 A-by-5-HTT and group-by-5-HTT interaction in GABA concentrations, with the 5-HTT high expressing genotype differing between groups and 5- $\mathrm{HT}_{1 \mathrm{~A}}$ genotypes. No significant effects were seen for glutamate or in rACC. To our knowledge, this is the first report of this serotonergic gene-togene interaction associated with mood, both among FMS (depression) and across groups (anxiety). Additionally, our findings provide evidence of an association between the serotonergic system and thalamic GABA concentrations, with individuals possessing genetically inferred high serotonergic signalling exhibiting the highest GABA concentrations, possibly enhancing GABAergic inhibitory effects via $5-\mathrm{HT}$.
\end{abstract}

Keywords: Serotonin, GABA, Genetic polymorphisms, 5- $\mathrm{HT}_{\mathrm{A}}$, Serotonin transporter, Fibromyalgia, Mood

*Correspondence: isabel.ellerbrock@ki.se

${ }^{\dagger}$ Rouslan Sitnikov and Eva Kosek contributed equally to this work

${ }^{1}$ Department of Clinical Neuroscience, Karolinska Insitutet, Nobels väg 9,

17177 Stockholm, Sweden

Full list of author information is available at the end of the article

\section{Introduction}

Within the central nervous system, serotonin (5-hydroxtryptamine, 5-HT) is synthesized in the brainstem raphe nuclei, with serotonergic projections ascending throughout the brain. The 5-HT metabolism is critically influenced by the main inhibitory serotonergic 5$\mathrm{HT}_{1 \mathrm{~A}}$ receptors and the serotonin transporter $(5-\mathrm{HTT})$. original author(s) and the source, provide a link to the Creative Commons licence, and indicate if changes were made. The images or other third party material in this article are included in the article's Creative Commons licence, unless indicated otherwise in a credit line to the material. If material is not included in the article's Creative Commons licence and your intended use is not permitted by statutory regulation or exceeds the permitted use, you will need to obtain permission directly from the copyright holder. To view a copy of this licence, visit http://creativecommons.org/licenses/by/4.0/. The Creative Commons Public Domain Dedication waiver (http://creativeco mmons.org/publicdomain/zero/1.0/) applies to the data made available in this article, unless otherwise stated in a credit line to the data. 
Presynaptic $5-\mathrm{HT}_{1 \mathrm{~A}}$ autoreceptors on serotonergic neurons control 5-HT release in terminal areas and decrease neuron firing, resulting in inhibited serotonergic signalling $[1,2]$. Activation of postsynaptic $5-\mathrm{HT}_{1 \mathrm{~A}}$ receptors, largely found in corticolimbic areas [3, 4], produces physiological responses determined by the target cell, e.g. antidepressant and antinociceptive effects. Additionally, 5-HTT regulates serotonergic signalling via 5-HT reuptake from the synaptic cleft into the pre-synaptic neuron, therefore controlling availability and duration of $5-\mathrm{HT}$ effects $[5,6]$. Given that serotonergic projections modulate a multitude of behavior, mechanisms influencing 5HT signalling are widely implicated in pain, mood and emotion [7-11].

Polymorphisms of serotonergic genes have been shown to affect mood $[8,12,13]$ and pain modulation [14-16]. Specifically, an abundance of inhibitory $5-\mathrm{HT}_{1 \mathrm{~A}}$ autoreceptors has been associated with the G-allele of a single nucleotide polymorphism in the $5-\mathrm{HT}_{1 \mathrm{~A}}$ receptor gene (rs6295) [17-19], linked to lower serotonergic signalling. Moreover, the low expression 5-HTT genotype has been linked to reduced binding in pre- and postsynaptic $5-\mathrm{HT}_{1 \mathrm{~A}}$ receptors [20-22]. Based on our previous study showing similar effects of the $5-\mathrm{HTT}_{\text {low }}$ and the $5-\mathrm{HT}_{1 \mathrm{~A}}$ */G genotypes on pain regulation in fibromyalgia subjects (FMS) and healthy controls (HC) [23], we would expect pain-relevant genotype interactions. Similar observations have been made in response to selective serotonin reuptake inhibitors (SSRIs) in depression [24-26], providing evidence for a serotonergic gene-gene interaction.

Dysfunctional pain inhibition has been demonstrated in FMS $[23,27,28]$, with lower pain-related activation in rostral anterior cingulate cortex (rACC) and thalamus, and reduced functional connectivity within the descending pain system $[29,30]$. Reduced $5-\mathrm{HT}$ in cerebrospinal fluid [31] and increased frequency of $5-\mathrm{HTT}_{\text {low }}$ in FMS [32] point to a dysregulated 5-HT system. 5 - HT is involved in controlling nociceptive transmission, where it can exert inhibitory or facilitatory effects [10,33], and in common FM comorbidities, e.g. depression [9, 34]. Glutamate and $\gamma$-aminobutyric acid (GABA), the key excitatory and inhibitory neurotransmitters in the brain, are crucially involved in nociceptive transmission [35] and have been found to be altered in some brain regions in FMS $[36,37]$. A recent study suggests widespread alterations in FMS in the GABAergic system [38]. While 5-HT as well as glutamate and GABA have been associated with $\operatorname{mood}[9,39,40]$ and modulating pain $[11,35,41]$, they are also intricately linked in their actions [42]. 5-HT modulates glutamate- and GABA-mediated effects in the spinal dorsal horn and may also elicit inhibitory effects on GABAergic neurons via $5-\mathrm{HT}_{1 \mathrm{~A}}$ receptors, e.g. in thalamic interneurons [43]. Specifically, higher serotonergic activity increases GABA release, thereby enhancing GABAergic inhibition and modulating sensory signals in the thalamus [43].

Here, we investigated the phenotypic influence of 5$\mathrm{HT}_{1 \mathrm{~A}}$ and 5-HTT polymorphisms in FMS and $\mathrm{HC}$ on (i) mood and pain-relevant characteristics, (ii) cerebral processing of evoked pressure pain in rACC and thalamus using functional magnetic resonance imaging (fMRI), and (iii) glutamate and GABA in rACC and thalamus using magnetic resonance spectroscopy (MRS). We hypothesized that the $5-\mathrm{HT}_{1 \mathrm{~A}} \mathrm{CC}$ and $5-\mathrm{HTT}_{\text {high }}$ genotypes, associated with more efficient serotonergic signalling, elicit a favourable effect regarding mood, pain sensitivity and influence cerebral pain processing. The analyses concerning glutamate and GABA are considered exploratory.

\section{Materials and methods \\ Sample}

The sample $(\mathrm{n}=127)$ consisted of 84 FMS (mean $47.2 \pm 7.8$ years) and $43 \mathrm{HC}$ (mean $48.2 \pm 7.6$ years), recruited as part of a larger project (see study plan https://osf.io/8zqak) [44-46]. Inclusion/exclusion criteria are described in Additional file 1.

\section{Procedure}

Data were collected over two consecutive days: on day one all participants provided saliva samples for genotyping and filled out questionnaires regarding pain catastrophizing (Pain Catastrophizing Scale, PCS [47]), depression (Beck's Depression Inventory, BDI [48]; Hospital Anxiety and Depression Scale, HAD-D [49]), anxiety (State-Trait Anxiety Inventory, STAI [50] and Hospital Anxiety and Depression Scale, HAD-A [49]) and reported current pain intensity (Visual analogue scale, VASnow). FMS also completed the Fibromyalgia Impact Questionnaire (FIQ) [51]. Higher scores indicate a higher degree of severity in all questionnaires (see Additional file 1 for details).

Pressure pain thresholds (PPTs) were determined to assess pain sensitivity. The handheld pressure algometer (Somedic Sales AB, Hörby, Sweden) had a round $1 \mathrm{~cm}^{2}$ rubber probe that was applied perpendicular to the surface. Manual force was applied at a steady rate (approximately $50 \mathrm{kPa} / \mathrm{s}$ ) and subjects pressed a response-button at the first sensation of pain [52]. PPTs were collected bilaterally across four anatomical sites with one assessment per site: supraspinatus muscle, elbow (lateral epicondyle), gluteus muscle and knee (medial fat pad proximal to the joint line). The average individual PPT across body sites was used in the analyses.

Pressure stimuli in the experimental pain paradigm were applied to participants' left calf using a cuff $(13 \times 85$ 
$\mathrm{cm}$ ) attached to a rapid cuff inflation system (E20/AG101, Hokanson, Bellevue, WA, USA). Stimulus intensity was individually calibrated to match $10 \mathrm{~mm}$ (P10) and $50 \mathrm{~mm}$ (P50) on a VAS ranging from $0 \mathrm{~mm}$ (no pain) to $100 \mathrm{~mm}$ (strongest imaginable pain). The procedure is described in Additional file 1 and in $[45,46]$.

On day two, participants underwent a MRI session, including the pressure pain paradigm during fMRI, in which color cues predicted the following stimulus intensity (described in detail in $[45,46])$. In short, a green circle $(2 \mathrm{~s})$ was followed by the individually calibrated low intensity pressure stimulus (P10, $5 \mathrm{~s})$ and a red circle (2 s) was followed by the individually calibrated medium intensity stimulus (P50, $5 \mathrm{~s}$ ). The green and red cues and subsequent pressure stimulations, P10 and P50, respectively, were each presented ten times in a pseudo-randomized manner. Participants were prompted to rate pain intensity on a computerized VAS ( $8 \mathrm{~s})$ after each stimulus.

\section{MRI data acquisition}

All MRI data were collected on a GE MR750 3 T scanner using an 8-channel head coil. Prior to MRS and functional MRI, high-resolution T1-weighted images were acquired (BRAVO, voxel size $1 \times 1 \times 1 \mathrm{~mm}, 176$ slices).

GABA and glutamate were measured in vivo using single-voxel proton MRS. The voxel position was verified by three-plane localizer images performed before every scan. Before each data acquisition gradient echo shimming, frequency and water suppression adjustments were performed automatically. The conventional point resolved spectroscopy (PRESS) was used with the following parameters: TR/TE/TE $1=2000 / 40 / 19 \mathrm{~ms}$, spectral bandwidth $5 \mathrm{kHz}, 4096$ time-domain data points and water suppression by three chemical shift selected suppression (CHESS) pre-pulses was used to ensure comparability with other studies. Six sharp outer volume suppression RF pulses surrounded voxel were applied to enhance the voxel definition. The voxel volume was 5.4 $\mathrm{mL}$ for $\mathrm{rACC}$ and $12 \mathrm{~mL}$ for thalamus. Both voxels were acquired with 128 number of averages and 8-step phase cycle, resulting in an acquisition time of 5 min per voxel.

Functional images comprised 42 axial slices (slice thickness $3 \mathrm{~mm}, 0.5 \mathrm{~mm}$ gap) and were acquired using a T2*-sensitive gradient echo-planar imaging sequence (TR $2 \mathrm{~s}$; TE $30 \mathrm{~ms}$; flip angle $70^{\circ}$; field of view $220 \times 220$ $\mathrm{mm}, 72 \times 72 \mathrm{~mm}$ matrix; $3 \times 3 \mathrm{~mm}$ in-plane resolution).

\section{Analysis of MRS data}

MRS data was pre-processed in MATLAB (The MathWorks, Natick, MA) and quantified in LCModel (version 6.3-1 K, s-provencher.com). The pre-processing included the S/N2-weighted MRS signal coil combining frequency and phase correction for every trace before final coherent averaging of the elementary MRS traces for each voxel. The LCModel basis set was simulated in MATLAB via quantum mechanical density matrix formalism using the PRESS pulse sequence timing parameters and the chemical shifts and J-coupling constants from [53, 54]. The basis set consisted of the following metabolites: aspartate, glutamate, glutamine, GABA, N-acetyl aspartate, myoand scyllo-inositol, taurine, ascorbate, glucose, creatine and phosphocreatine, choline and glycero-phosphorylcholine, $\mathrm{N}$-acetyl aspartate-glutamate, glutathione, alanine, lactate, ethanolamine and phosphorylethanolamine. Calibration of the basis set was performed using a MRS phantom (BRAINO+GABA, GE Healthcare). The MRS data were quantified using the ratio to (i) total creatine (7-mM assumed value, relative) and (ii) total voxel water concentration (absolute). Endogenous water concentration was estimated by using MRS voxel co-registration with segmented structural 3D T1-weighted images (grey matter, white matter, CSF) in native space in FSL (version 5, FMRIB Software Library). The obtained tissue volumes were then masked by the voxel and partial volume estimates for each tissue type that was used to correct the total water concentration.

All analyses were carried out separately for rACC and thalamus using the absolute and relative concentrations of glutamate and GABA. MRS data were acquired of 108 participants in $\mathrm{rACC}(\mathrm{FMS}=68, \mathrm{HC}=40)$ and 116 participants in thalamus (FMS $=74, \mathrm{HC}=42$ ).

\section{Analysis of fMRI data}

Processing and analysis of functional data was performed using statistical parametric mapping (SPM12, Wellcome Trust Centre for Neuroimaging) running under MATLAB (version R2015b). Anatomical and functional scans were first reoriented manually to the anterior commissure. Volumes were realigned to the mean volume using a six-parameter affine transformation. Then, the anatomical T1-weighted image was coregistered to the functional images. Functional images were spatially normalized to a standard Montreal Neurological Institute (MNI) template and finally smoothed using an isotropic Gaussian kernel (FWHM, $6 \mathrm{~mm}$ ). Framewise displacement (FD) was used to assess relative head movement from one frame to another using the sum of the absolute values of the derivatives of the realignment parameters [55]. As a consequence, six participants (four FMS, two HC) were excluded from further analyses due to excessive head motion (FD $>0.5$ in $>15 \%$ of the images). There were no differences in FD between FM and HC (Wilcoxon rank sum test, $\mathrm{Z}=1.58, p=0.1145)$. Data analysis was performed using the general linear model implemented in SPM12-7219. First level analysis included temporal 
high-pass filtering (cut-off $128 \mathrm{~s}$ ) and correction for autocorrelations using first-order autoregressive modelling. The following conditions were modelled on the individual level: pressure stimulations for two intensities (P10/ P50), two cue/anticipation phases (red preceding P50/ green preceding P10) and the rating period. Six realignment-derived parameters capturing motion were added as regressors of no interest.

Region of interest (ROI) analyses were performed to link evoked pain-related blood-oxygen-level-dependent (BOLD)-response (during P50) to metabolites in brain areas relevant to pain-processing and differences between FMS and HC have been observed [29, 30]. Specifically, raw, unscaled parameter estimates (weighted combinations of beta-values) were extracted from individual (first-level) maps for each subject for the contrast P50 > implicit baseline, i.e. inter-trial and waiting periods, averaged within custom-built masks of right rACC and bilateral thalamus, resulting in one value per person and ROI. Masks were created using MarsBar (http://marsb ar.sourceforge.net/) with the aim of matching the single MRS voxel. BOLD-signal was averaged over all voxels in brain masks, allowing individually varying number of voxel contributions per subject. This approach was chosen as the extraction of BOLD-response from a mask, i.e. collapsed across voxels within the region, decreases noise and provides comparability with MRS data.

Functional MRI data were collected for 120 participants, of which 15 data sets were excluded from further analysis due to excessive head motion $(n=6)$, structural brain anomalies $(n=1)$ and incomplete data sets due to technical issues and drop-outs $(n=8)$. The fMRI analyses included data of 105 participants, of which four data sets were missing genotyping information. Final results are presented for $\mathrm{n}=101$ participants $(\mathrm{FMS}=68, \mathrm{HC}=33)$.

\section{Genotyping}

Saliva samples (Oragene G500) were collected from all participants for the purpose of genotyping, which was performed blind to phenotypic information. Individuals were genotyped regarding the $5-\mathrm{HT}_{1 \mathrm{~A}}$ gene (rs6295) and dichotomized into major allele homozygotes (CC) and minor G-allele carriers (CG and GG, i.e. */G) [15, 23].

5 -HTT is coded by the SLC6A4 gene, which contains several functional polymorphisms that alter genetic expression, including 5-HTTLPR (consists of a long allele, L, and a short allele, S) and rs25531 (A/G substitution), which have been suggested to efficiently study 5-HTT. Given its proposed efficacy [56] and in line with our previous study [23], we examined 5-HTTLPR/ rs 25531 jointly, resulting in functional groupings of high
$\left(\mathrm{L}_{\mathrm{A}} / \mathrm{L}_{\mathrm{A}}\right)$, intermediate $\left(\mathrm{L}_{\mathrm{A}} / \mathrm{L}_{\mathrm{G}}\right.$ and $\left.\mathrm{L}_{\mathrm{A}} / \mathrm{S}_{\mathrm{A}}\right)$ and low $\left(\mathrm{S}_{\mathrm{A}} / \mathrm{S}_{\mathrm{A}}\right.$ and $\mathrm{S}_{\mathrm{A}} / \mathrm{L}_{\mathrm{G}}$ ) expression of 5 -HTT.

TaqMan single nucleotide polymorphism genotyping assays and ABI 7900 HT instrument (Applied Biosystems (ABI), Foster City, CA, USA) was used for 5- $\mathrm{HT}_{1 \mathrm{~A}}$ genotyping. Polymerase chain reactions (PCRs), with a total volume of $5 \mathrm{~mL}$, were performed in 384-well plates containing $2.5 \mathrm{~mL}$ Universal Master Mix (UMM) and 5 ng dried-down genomic DNA per well. The PCR amplification protocol included 2 holds, $50{ }^{\circ} \mathrm{C}$ for $2 \mathrm{~min}$ and denaturation at $95^{\circ} \mathrm{C}$ for $10 \mathrm{~min}$, followed by 45 cycles at $92{ }^{\circ} \mathrm{C}$ for $15 \mathrm{~s}$ and $60^{\circ} \mathrm{C}$ for $1 \mathrm{~min}$.

Two fragments, 487 bp (short) and 530 bp (long), were amplified by PCRs for the genotyping of the triallelic 5-HTTLPR. Each PCR reaction contained $50 \mathrm{ng}$ DNA, $0.2 \mathrm{mM}$ deoxynucleotide triphosphate (dNTP), 0.4 mMof primer 17P-3F (59-ggcgttgccgctctgaatgc-39), 0.4 $\mathrm{mM}$ primer 17P-3R (59-gagggactgagctggacaaccac-39), $0.05 \mathrm{~mL}$ Qiagen HotStar Polymerase, $1 \mathrm{M}$ Q-solution, and finally $1 \times$ buffer. Samples were amplified on Biorad Tetrade (BIORAD, Hercules, CA, USA) with an initial denaturation for $10 \mathrm{~min}$ at $95{ }^{\circ} \mathrm{C}$ followed by 33 cycles consisting of denaturation for $30 \mathrm{~s}$ at $95^{\circ} \mathrm{C}$, annealing for $30 \mathrm{~s}$ at $57^{\circ} \mathrm{Cand}$ elongation for $5 \mathrm{~min}$ at $72^{\circ} \mathrm{C}$, and finally followed by another elongation step for $5 \mathrm{~min}$ at $72{ }^{\circ} \mathrm{C}$. Eight microliters of the PCR reactions were separated for $2 \mathrm{~h}$ at $100 \mathrm{~V}$ by gel electrophoresis in TBE buffer on a $2.5 \%$ agarose gel containing GelRed and visualized using ultraviolet light. To determine $r s 25531,10 \mathrm{~mL}$ of the PCR product was digested with $0.1 \mathrm{~mL}$ MSP1 (New England Biolabs, Ipswich, MA, USA) and $1 \mathrm{~mL}$ buffer per sample for $12 \mathrm{~h}$ at $37{ }^{\circ} \mathrm{C}$. The MSP1 restriction enzyme breaks the 59-C/CGG9 sequence that gives a fragment of 342 base pairs, one of 127 and finally one of 62 base pairs which constitutes the LA allele, whereas the 298, 127, and 62 base pairs is the SA allele, the 173, 166, 127, and 62 base pairs for the LG allele, and finally the 166, 130, 127, and 62 for the SA allele. Fragments were run on a 4\% agarose gel (3\% normal agarose and 1\% low melting agarose) containing GelRed initially for $15 \mathrm{~min}$ at $70 \mathrm{~V}$ followed by 2 more hours at $100 \mathrm{~V}$. The gels were then visualized with ultraviolet light.

The saliva sample of one FMS was missing and, therefore, not genotyped for $5-\mathrm{HT}_{1 \mathrm{~A}}$ and 5 -HTT. In addition, the 5-HTT genotype could not be determined in two FMS and three HC, as the PCRs did not produce secure read-outs.

\section{Statistical analyses}

Analyses were performed using $\mathrm{R}$ version 4.0.3 [57]. ANOVAs and linear mixed effects models were performed using the package afex [58]. Follow-up tests using emmeans [59] were adjusted for multiple comparisons 
using Holm's method [60]. Reported p-values are twosided and $p<0.05$ was considered statistically significant.

\section{Anxiety and pain sensitivity in all participants}

Effects on PPTs as a measure of pain sensitivity, calibrated input pressure, as well as state and trait anxiety (STAI) were analyzed in separate ANOVAs with group (FMS/HC), 5- $\mathrm{HT}_{1 \mathrm{~A}}$ (CC/G-carriers) and 5-HTT (high/ intermediate/low expression) as factors.

\section{Clinically relevant characteristics in FMS}

Depression (BDI, HAD-D), current pain (VASnow) and pain catastrophizing (PCS) were first tested for group differences using Wilcoxon test or Welch test. Next, these pain-relevant measures and overall FM impact (FIQ) were tested for effects of 5-HT $1 \mathrm{~A}$ and 5-HTT in separate ANOVAs in FMS only. This approach was taken as acute pain and depression were exclusion criteria for $\mathrm{HC}$, thus, the data lacked sufficient variability and the focus of this study was serotonin-related genes and their potential interaction. Note that opposed to the STAI, the HAD-A was considered a clinical measure, given its clinical target group.

A linear mixed model was performed to test for differences in calibrated input pressure with fixed effects pressure level (P10/P50), group, $5-\mathrm{HT}_{1 \mathrm{~A}}$ and $5-\mathrm{HTT}$, including all two-way interactions and random intercept per subject. Variance of the random effect was estimated using restricted maximum likelihood and Satterthwaite approximation was used for degrees of freedom to obtain p-values.

\section{fMRI and MRS data}

In separate analyses for right $\mathrm{rACC}$ and bilateral thalamus, group (two levels), $5-\mathrm{HT}_{1 \mathrm{~A}}$ (two levels) and 5-HTT (three levels) were tested as predictors with the outcome variables (i) extracted BOLD-signal during evoked pain (P50), (ii) glutamate and (iii) GABA. Each ANOVA tested for interactions between $5-\mathrm{HT}_{1 \mathrm{~A}}$ and 5 - $\mathrm{HTT}$, as well as between group and each gene. Glutamate and GABA analyses were performed twice, for relative and absolute metabolite levels.

\section{Correlations and mediation analysis}

Spearman's rho was used to correlate BOLD-response during evoked pain and baseline MRS data in $\mathrm{ACC}$ and thalamus to test for relationships between glutamate concentrations, GABA concentrations and BOLD-signal, respectively.

Next, we explored whether GABA mediated the group effect on pain-evoked BOLD-signal. The hypothesis is that negative BOLD-signal is driven by decreased neuronal activity linked to inhibitory GABAergic neurotransmission. GABA would be considered a significant mediator if the indirect effect was significant while the previously direct group effect on BOLD-signal became nonsignificant after accounting for GABA.

\section{Results}

Frequencies of $5-\mathrm{HT}_{1 \mathrm{~A}}$ and 5 - $\mathrm{HTT}$ genotypes showed no significant relationship ( $p=0.44$, Fisher's exact test), negating potential concerns of confounding effects on the tested phenotypes. Genotype frequencies were comparable between groups (Additional file 2: Table S1).

\section{Mood, anxiety and pain-relevant characteristics}

As expected, significant group differences were observed in BDI, HAD, PCS and VASnow, with FMS showing higher current pain, higher levels of anxiety, depression and pain catastrophizing (Table 1). Additional FMS characteristics are presented in Table 1.

In FMS, there were no effects of $5-\mathrm{HT}_{1 \mathrm{~A}}$ or 5 - $\mathrm{HTT}$ in pain catastrophizing (PCS), current pain (VASnow), anxiety (HAD-A), FM impact (FIQ) or pain duration (Table 2).

Assessing depressive symptoms in FMS using the HAD-D, there was a significant $5-\mathrm{HT}_{1 \mathrm{~A}}$-by-5-HTT interaction (Table 2), with 5- $\mathrm{HT}_{1 \mathrm{~A}} \mathrm{CC}$ showing higher values and therefore more negative characteristics than $* / G$, unless coupled with $5-\mathrm{HTT}_{\text {high }}$. Specifically, $5-\mathrm{HT}_{1 \mathrm{~A}} \mathrm{CC}$ paired with $5-\mathrm{HTT}_{\text {high }}$ resulted in lowest values, indicative of less depressive symptoms. Followup tests revealed significant differences between 5$\mathrm{HT}_{1 \mathrm{~A}}$ genotypes for all 5 -HTT genotypes $\left(5-\mathrm{HTT}_{\text {high: }}\right.$ : $t(75)=-2.37, p=0.041 ; 5$-HTT intermediate $: t(75)=4.60$, $\left.p<0.001 ; \quad 5-\mathrm{HTT}_{\text {low }}: t(75)=2.32, \quad p=0.041\right)$, albeit

Table 1 Participant characteristics and group differences for clinical parameters

\begin{tabular}{lllll}
\hline & $\begin{array}{l}\text { FMS } \\
(\mathbf{n = 8 4 )}\end{array}$ & $\begin{array}{l}\text { HC } \\
(\mathbf{n}=\mathbf{4 3})\end{array}$ & \multicolumn{2}{l}{ Group difference } \\
\hline Age & $47.2(7.8)$ & $48.1(7.6)$ & $t(87)=-0.63$ & $p=0.53$ \\
VASnow & $53.3(22.0)$ & $2.2(3.2)$ & $t(90)=20.80$ & $p<0.001$ \\
PCS & $18.3(10.8)$ & $4.7(7.0)$ & $W=3170$ & $p<0.001$ \\
HAD-A & $7.9(4.3)$ & $3.1(2.9)$ & $t(116)=7.47$ & $p<0.001$ \\
HAD-D & $7.2(4.0)$ & $1.1(1.5)$ & $t(116)=12.29$ & $p<0.001$ \\
BDI & $16(7.7)$ & $0.5(1.4)$ & W=3544 & $p<0.001$ \\
Tenderpoints & $16.4(1.8)$ & - & - & - \\
$\begin{array}{l}\text { Pain duration } \\
\text { (months) }\end{array}$ & $185.6(104.2)$ & - & - & - \\
\hline
\end{tabular}

Reported are mean (standard deviation) and Wilcoxon Rank Sum test or Welch two-sample $t$-test

FMS fibromyalgia subjects, $H C$ healthy controls, VASnow current pain on visual analogue scale, PCS Pain Catastrophizing Scale, HAD-A Hospital Anxiety and Depression Scale (anxiety subscale), HAD-D Hospital Anxiety and Depression Scale (depression subscale), BDIBeck's Depression Inventory 
Table 2 ANOVAs for pain-relevant characteristics in fibromyalgia subjects

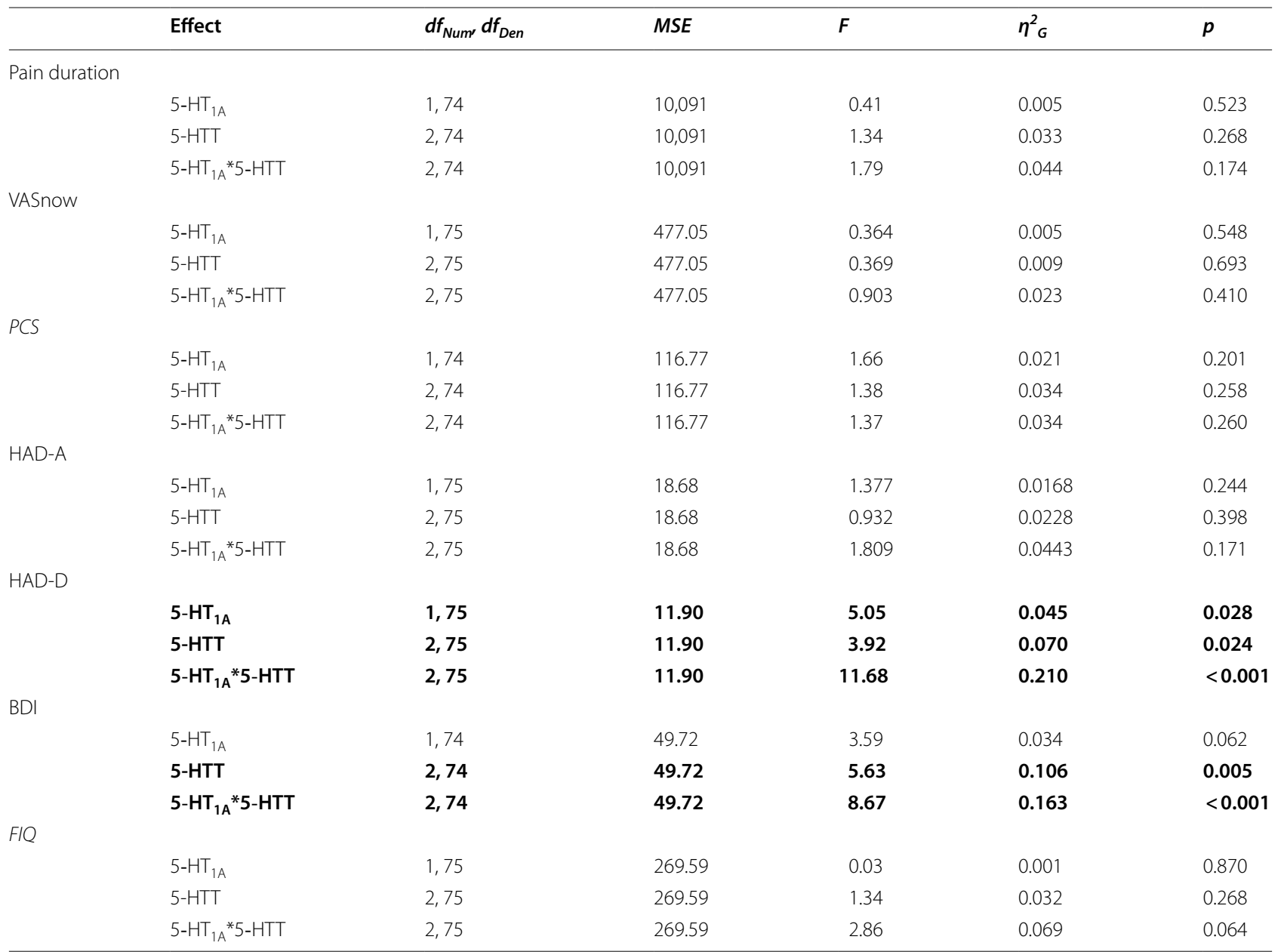

PCS Pain Catastrophizing Scale, VASnow current pain on visual analogue scale, HAD-A Hospital Anxiety and Depression Scale (anxiety subscale), HAD-DHospital Anxiety and Depression Scale (depression subscale), BDIBeck's Depression Inventory, FIQ Fibromyalgia Impact Questionnaire, $d f_{\text {Num }}$ numerator degree of freedom, $d f_{\text {Den }}$ denominator degrees of freedom, MSE mean square error, $\eta_{G}^{2}$ generalized eta-squared. Effects significant at $p<0.05$ are depicted in bold

in different directions (Fig. 1a). The analysis of BDI scores resulted in a similar pattern (Table 2). Followup tests on the $5-\mathrm{HT}_{1 \mathrm{~A}} \times 5-\mathrm{HTT}$ interaction in BDI scores revealed that $5-\mathrm{HT}_{1 \mathrm{~A}}$ genotypes differed significantly in $5-\mathrm{HTT}_{\text {intermediate }}(t(74)=14.58, p<0.001)$ but not in $5-\mathrm{HTT}_{\text {high }}(t(75)=-1.77, p=0.162)$ or $5-\mathrm{HTT}_{\text {low }}$ $(t(75)=1.23, p=0.224)$ (Fig. 1b).

Interestingly, an interaction between serotoninrelevant genes was also observed in the analysis of anxiety including both FMS and HC. In state anxiety (STAI-S), a significant $5-\mathrm{HT}_{1 \mathrm{~A}}$-by-5-HTT interaction $\left(\mathrm{F}(2,109)=3.28, \quad \eta_{G}^{2}=0.042, p=0.041\right)$ was found in addition to FMS displaying more anxiety than $\mathrm{HC}$ (mean difference $\mathrm{FM}-\mathrm{HC}=13.7$ points $) \quad(\mathrm{F}(1,109)=32.16$, $\eta_{G}^{2}=0.207, p<0.001$ ) (Additional file 3: Fig. S1). Similar to analyses of depression in FMS, a homozygous 5$\mathrm{HT}_{1 \mathrm{~A}} \mathrm{CC}$ genotype in combination with high expressing 5-HTT showed lower values, i.e. less (current) anxiety, than individuals with low- vs. intermediate expressing 5-HTT genotypes (Fig. 1c). In follow-up analyses, however, the differences between $5-\mathrm{HT}_{1 \mathrm{~A}}$ in 5 - $\mathrm{HTT}$ genotypes were not significant after multiple comparison correction. In trait anxiety (STAI-T), a very similar pattern was found (Fig. 1d), but only significant group differences emerged (mean difference $\mathrm{FM}-\mathrm{HC}=13.9$ points) $\left(\mathrm{F}(1,109)=49.29, \eta^{2}{ }_{G}=0.285, p<0.001\right)$, whereas the 5$\mathrm{HT}_{1 \mathrm{~A}}$-by-5-HTT interaction did not reach significance $\left(\mathrm{F}(2,109)=8.67, \eta^{2}{ }_{G}=0.163, p=0.069\right)$.

\section{PPT}

PPTs, a measure of pain sensitivity, differed between groups, showing FMS $(\mathrm{M}=152, \mathrm{SD}=63)$ were overall more pain sensitive than $\mathrm{HC}(\mathrm{M}=311, \mathrm{SD}=99)$ $\left(\mathrm{F}(1,110)=83.83, \eta_{G}^{2}=0.386, p<0.001\right)$. In addition, a significant group-by-5- $\mathrm{HT}_{1 \mathrm{~A}}$ interaction was observed $\left(\mathrm{F}(1,110)=7.87, \quad \eta^{2}{ }_{G}=0.036, \quad p=0.006\right) . \quad$ Follow-up 

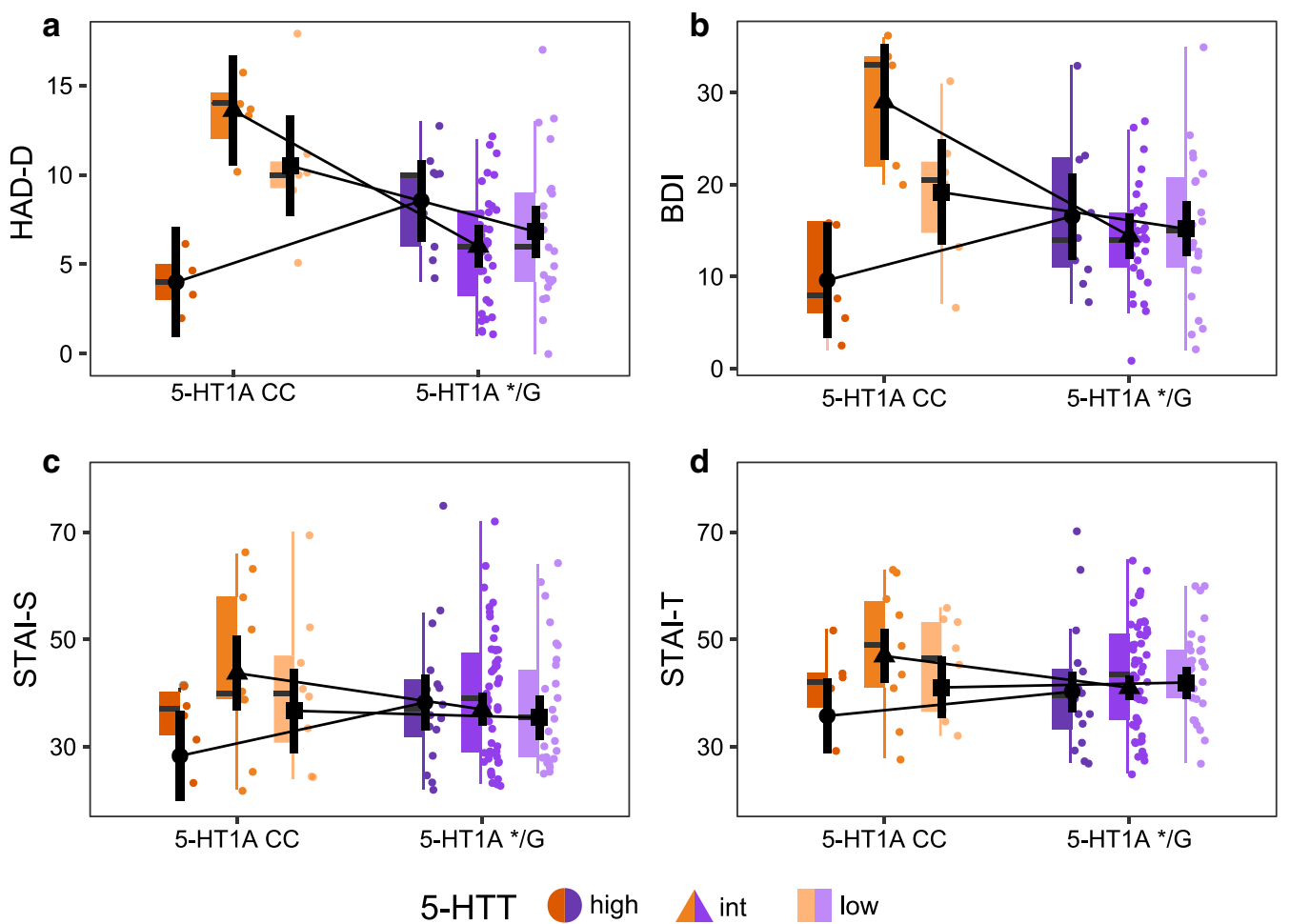

Fig. 1 Gene-by-gene interaction in measures of depression in fibromyalgia subjects (FMS) $(n=81)$ and anxiety in all participants $(n=120)$. a FMS displayed a significant 5- $\mathrm{HT}_{1 \mathrm{~A}}$-by-5-HTT interaction in HAD-D (Hospital Anxiety and Depression Scale, Depression subscale) scores and b BDI (Beck's depression inventory) with 5- $\mathrm{HT}_{1 \mathrm{~A}} \mathrm{CC}$ paired with the 5-HTT high expressing genotype resulting in lowest depression values. c A similar pattern was observed in STAI (State-trait anxiety inventory) data obtained from all participants (FMS and healthy controls) with both STAI-S (state subscale) and d STAI-T (trait subscale) displaying serotonin-relevant gene-gene interactions in addition to significant group differences (see Additional file 3: Fig. S1). Plotted are black circles, triangles and squares representing estimated marginal means with $95 \%$ confidence interval combined with colored boxplots, with the line representing the median, the upper and lower box representing the 25th (Q1) and 75th (Q3) percentile, i.e. the interquartile range $(\mathrm{IQR})$, and whiskers represent $\mathrm{Q} 1-$ and $\mathrm{Q} 3+1.5 * \mathrm{QR}$. Raw data is plotted in the background

tests revealed that $5-\mathrm{HT}_{1 \mathrm{~A}}$ genotypes differed significantly in $\mathrm{HC}(t(110)=3.16, p=0.004)$ but not in FMS $(t(110)=-0.24, p=0.808)$. Homozygous $\mathrm{C}$-allele carriers in $\mathrm{HC}(\mathrm{M}=391, \mathrm{SD}=109)$ displayed significantly higher PPTs than HC G-carriers $(M=297, S D=92)$, while there was no significant difference observed between FMS $\mathrm{CC}(\mathrm{M}=150, \mathrm{SD}=55)$ and $\mathrm{FMS} \mathrm{G}$-carriers $(\mathrm{M}=152$, $\mathrm{SD}=65$ ) (Additional file 4: Fig. S2a).

\section{Input pressure}

There were no differences between $5-\mathrm{HT}_{1 \mathrm{~A}}$ or 5 -HTT or interactions with group or pressure level (Additional file 2: Table S2). As we have previously reported $[45,46]$, FMS displayed higher pain sensitivity than $\mathrm{HC}$, i.e. they required less pressure stimulation to reach 10/100 VAS and 50/100 VAS, respectively. Additionally, a main effect for the pressure level was found. The effects of group and pressure level were qualified by a significant groupby-pressure interaction (Additional file 4: Fig. S2b), indicating a larger difference between groups in P50 (mean difference $\mathrm{HC}$-FM $=96 \mathrm{mmHg}$ ) than $\mathrm{P} 10$ (mean difference $\mathrm{HC}-\mathrm{FM}=52 \mathrm{mmHg}$ ).

\section{fMRI}

There were no significance differences between serotonergic genotypes or groups in BOLD-signal during evoked pressure pain in rACC (Table 3, Fig. 2a).

In thalamus, pain-evoked BOLD-signal compared to implicit baseline differed significantly between groups with $\mathrm{HC}$ showing more deactivation than FM (Table 3, Fig. 2b). No effect for $5-\mathrm{HT}_{1 \mathrm{~A}}, 5-\mathrm{HTT}$ or any interaction was observed.

\section{MRS}

No significant effects of group, 5- $\mathrm{HT}_{1 \mathrm{~A}}, 5-\mathrm{HTT}$ or significant interactions were found regarding GABA or glutamate concentrations in rACC (Additional file 2: Table S3). Absolute metabolites based on quantification in relation to tissue water showed similar results. 
Table 3 ANOVAs for extracted BOLD-signal during evoked pain (P50) in rACC and thalamus

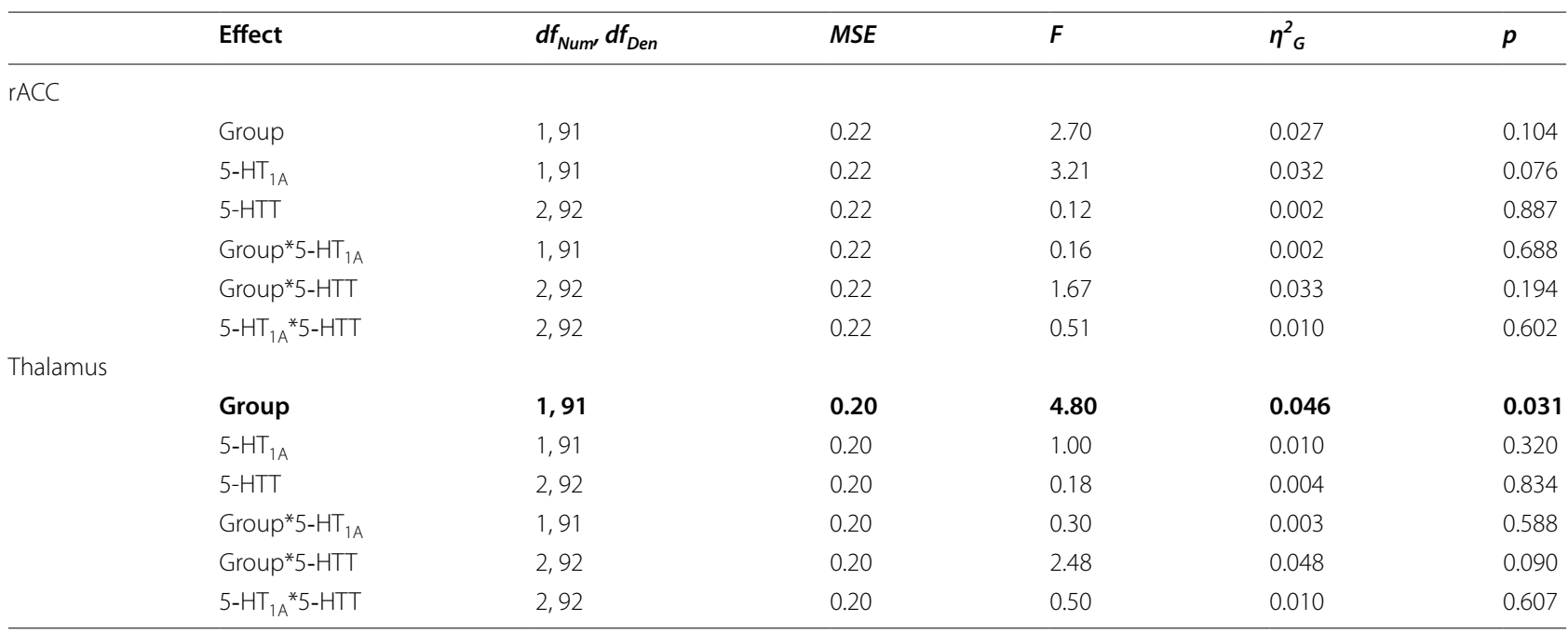

$d f_{\text {Num }}$ numerator degree of freedom, $d f_{\text {Den }}$ denominator degrees of freedom, MSE mean square error, $\eta_{G}^{2}$ generalized eta-squared. Effects significant at $\mathrm{p}<0.05$ are depicted in bold

In thalamus, there was a significant effect of $5-\mathrm{HT}_{1 \mathrm{~A}}$ with $5-\mathrm{HT}_{1 \mathrm{~A}} \mathrm{CC}$ having higher GABA concentrations (Table 4). This observed main effect was qualified by a statistically significant $5-\mathrm{HT}_{1 \mathrm{~A}}$-by-5-HTT interaction, with significant $5-\mathrm{HT}_{1 \mathrm{~A}}$ differences $(\mathrm{CC}>* / \mathrm{G})$ in $5-\mathrm{HTT}_{\text {high }}$ $(t(101)=2.80, p=0.018)$ but not in $5-\mathrm{HTT}_{\text {intermediate }}$ $(t(101)=-0.48, p=0.632)$ or $5-\mathrm{HTT}_{\text {low }}(t(101)=1.48$, $p=0.283$ ) (Fig. 2c). Additionally, a significant group-by5 -HTT interaction was found in GABA, revealing FMS and $\mathrm{HC}$ differed in $5-\mathrm{HTT}_{\text {high }}(t(101)=-2.45, p=0.048)$ (HC> FMS) but not in 5-HTT intermediate $(t(101)=0.86$, $p=0.508)$ or $5-\mathrm{HTT}_{\text {low }}(t(101)=1.15, p=0.508)$ (Fig. 2c). Including a three-way interaction $\left(5-\mathrm{HT}_{1 \mathrm{~A}}\right.$-by-5-HTTby-group) did not significantly change the results and was removed from the final analysis. No effect of serotonin-related genotypes or group were found in glutamate. Water-scaled absolute glutamate and GABA concentrations showed similar results (Table 4, Fig. 2c). Raw values of metabolite concentrations are presented in Additional file 2: Table S4.

\section{Correlations and mediation analysis}

There were no correlations between BOLD-signal during evoked pain processing and glutamate or GABA concentrations at baseline in either $\mathrm{ACC}$ or thalamus.

We explored whether the BOLD group effect in thalamus during evoked pain was mediated via GABA. Here, group predicted BOLD-response, explaining a significant proportion of variance $\left(\mathrm{R}^{2}=0.05, \mathrm{~F}(1,98)=5.58\right.$, $p=0.02)$. However, as group was not a significant predictor of the potential mediator GABA $\left(R^{2}=0.01, F(1\right.$,
$98)=1.27, p=0.26$ ), testing for a mediation effect was unsuitable.

\section{Discussion}

The present multimodal imaging study provides evidence for an association between serotonergic signalling and thalamic GABA concentrations. Regarding thalamic GABA concentrations, a significant effect was found for $5-\mathrm{HT}_{1 \mathrm{~A}}$, which was qualified by a $5-\mathrm{HT}_{1 \mathrm{~A}}-$ by-5-HTT interaction with higher relative and absolute GABA concentrations in $5-\mathrm{HT}_{1 \mathrm{~A}} \mathrm{CC}$ compared to G-carriers, specifically in the 5-HTT high expressing genotype. Additionally, a group-by-5-HTT interaction revealed higher GABA concentrations in $\mathrm{HC}$ than FMS with $5-\mathrm{HTT}_{\text {high }}$ but not $5-\mathrm{HTT}_{\text {intermediate }}$ or $5-\mathrm{HTT}_{\text {low }}$. Our data indicate an association between serotonergic signalling and thalamic GABA levels, with individuals with genetically inferred more pronounced serotonergic signalling $\left(5-\mathrm{HT}_{1 \mathrm{~A}} \mathrm{CC}\right.$ and $5-\mathrm{HTT}_{\text {high }}$ ) presenting with higher GABA concentrations. Furthermore, among

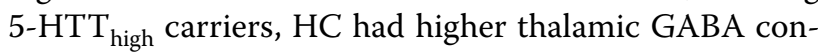
centrations than FMS, which is consistent with the lower serotonergic metabolism in FMS [31, 61]. Cerebral processing of evoked pressure pain differed between groups with $\mathrm{HC}$ showing more thalamic deactivation than FMS, an effect not mediated by thalamic GABA concentrations, but no significant effects of $5-\mathrm{HT}_{1 \mathrm{~A}}$ or 5 - HTT were observed. No associations were found between serotonergic genotypes and sensitivity to pressure level used to evoke pain in FMS, however, a group-by-5- $\mathrm{HT}_{1 \mathrm{~A}}$ interaction was found in PPTs, with CC homozygotes displaying higher pain thresholds than G-carriers in $\mathrm{HC}$. 

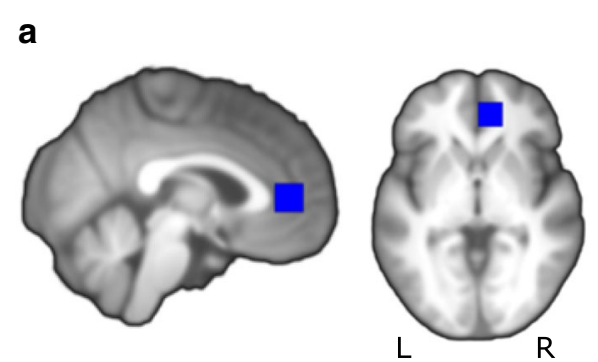

b

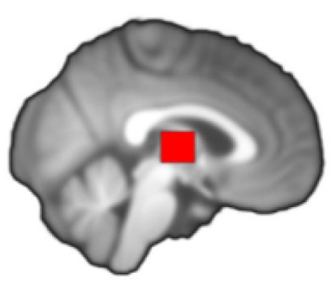

C
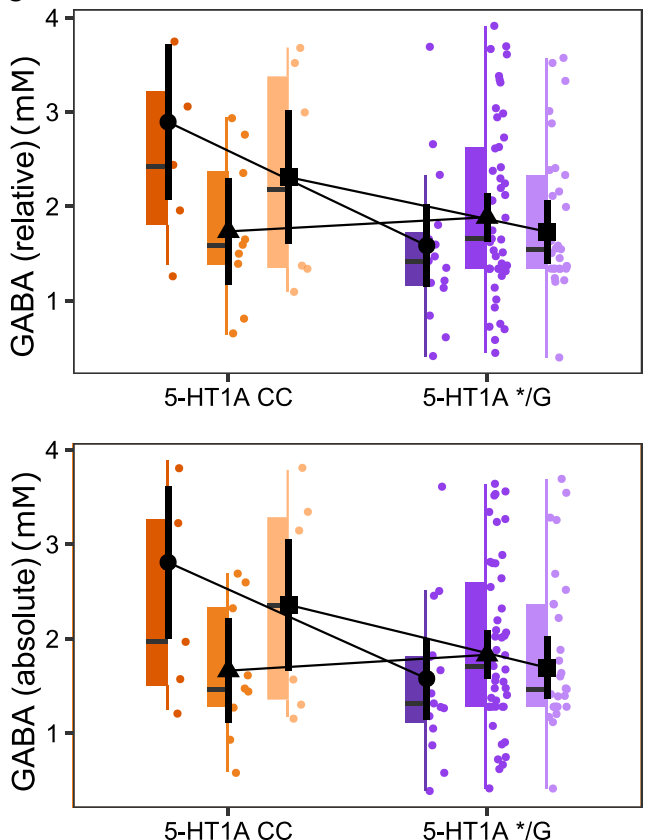

5-HTT

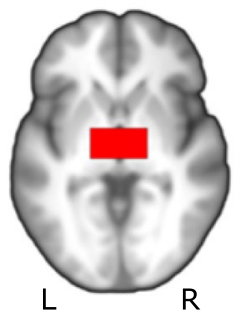

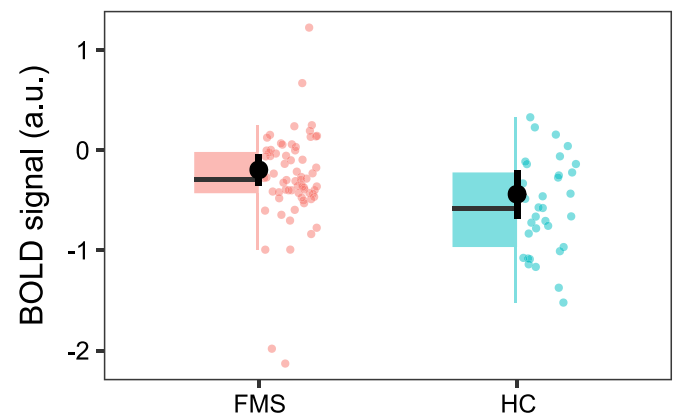
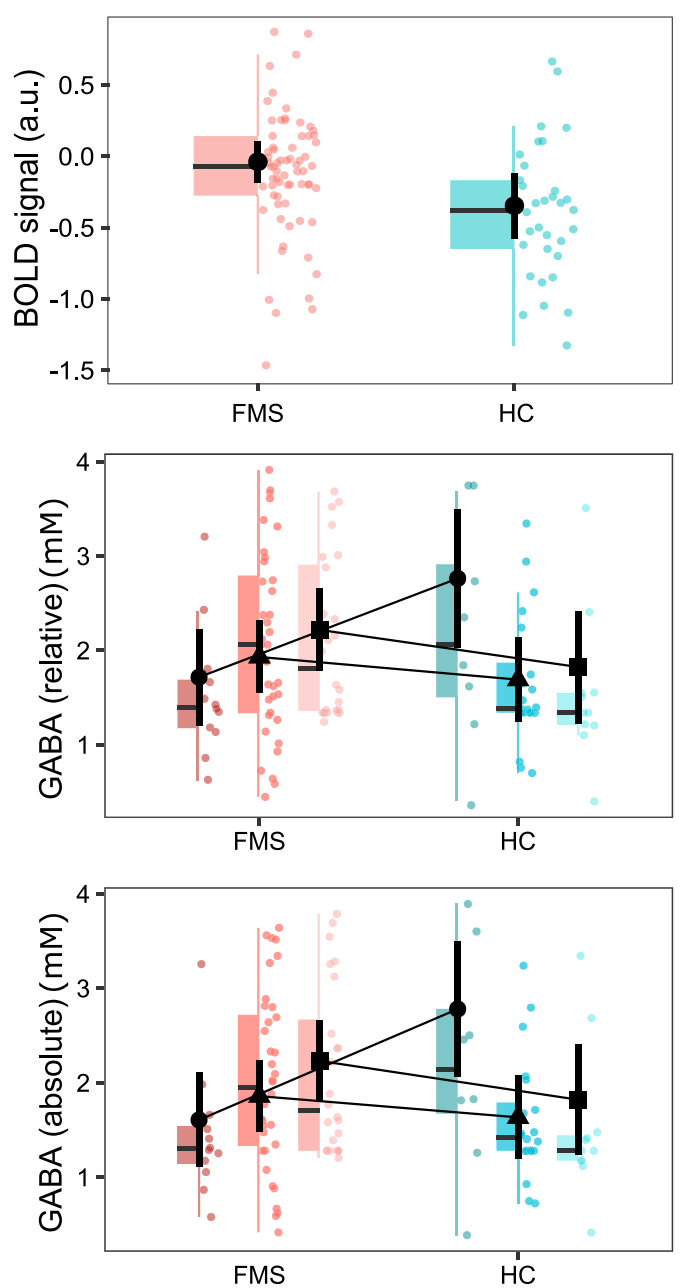

5-HTT

int

low

Fig. 2 Extracted BOLD-signal and GABA concentration. Fibromyalgia subjects (FMS) $(n=68)$ showed a similar pattern of lower pain-evoked BOLD-signal as healthy controls (HC) $(n=33)$ in a right rACC and $\mathbf{b}$ bilateral thalamus. This effect, however, was only significant in thalamus. $\mathbf{c}$ In thalamic GABA concentrations ( $F M S=74, \mathrm{HC}=42$ ), there was a significant 5- $\mathrm{HT}_{1 \mathrm{~A}}$-by-5-HTT interaction, as well as a significant group-by-5-HTT interaction. A comparable pattern was observed in both relative (upper row) and absolute GABA (lower row) concentrations. Plotted are black circles, triangles and squares representing estimated marginal means with the associated black vertical lines being $95 \%$ confidence intervals. In the colored boxplots, the horizontal line represents the median, the upper and lower box representing the 25th (Q1) and 75th (Q3) percentile, i.e. the interquartile range (IQR), and whiskers represent Q1 - and Q3+1.5*IQR. Raw data is plotted in the background. a.u. arbitrary units, $\mathrm{mM} \mathrm{millimole,} L$ left, $R$ right 
Table 4 ANOVAs for relative and absolute glutamate and GABA concentrations in thalamus

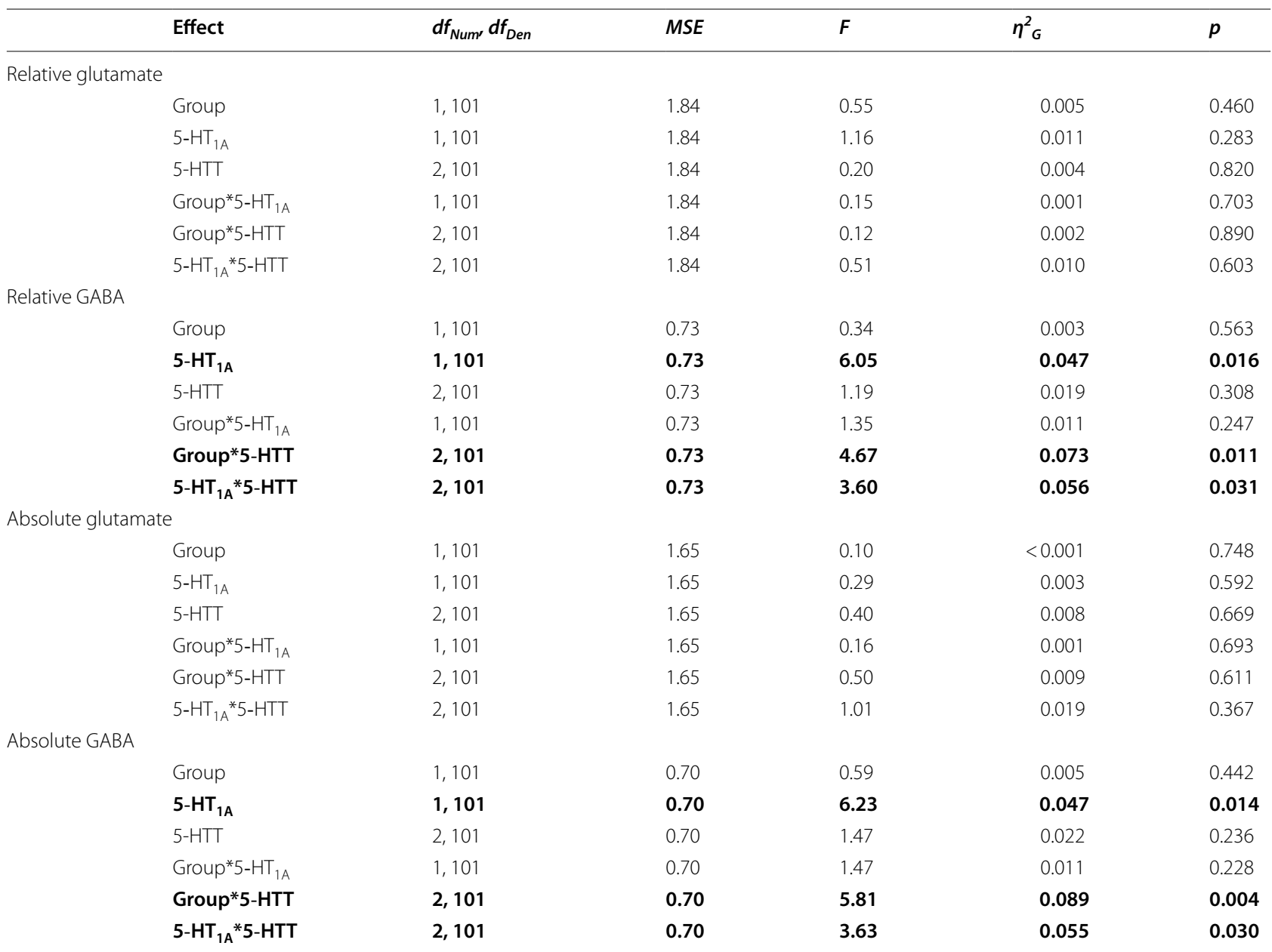

$d f_{\text {Num }}$ numerator degree of freedom, $d f_{\text {Den }}$ denominator degrees of freedom, MSE mean square error, $\eta_{G}^{2}$ generalized eta-squared. Effects significant at $p<0.05$ are depicted in bold

Finally, significant interactions between the serotonergic genes in mood were found among FMS (depression) and across groups (anxiety). To our knowledge, this is the first evidence of this gene-to-gene interaction indicating a favourable effect on mood of genetically inferred high serotonergic signalling $\left(5-\mathrm{HT}_{1 \mathrm{~A}} \mathrm{CC}\right.$ paired with 5- HTT $_{\text {high }}$ ).

Similar patterns of 5 - $\mathrm{HT}_{1 \mathrm{~A}}$-by-5-HTT interactions were observed for measures of mood, with $5-\mathrm{HT}_{1 \mathrm{~A}} \mathrm{CC}$ displaying lowest depression scores in combination with 5-HTT ${ }_{\text {high }}$ (Fig. 1a, b). This is in line with the assumption that individuals with a more efficient serotonergic system display less depressive symptoms, based on the combined effect of two genotypes producing higher 5-HT signalling. Previous literature points in the same direction: depressed patients with the $5-\mathrm{HT}_{1 \mathrm{~A}} \mathrm{CC}$ genotype responded better compared to G-carriers to antidepressants $[62,63]$ and $5-\mathrm{HTT}_{\text {low }}$ individuals with chronic pain displayed higher depression scores than intermediate and high expression genotypes [64]. The apparent vulnerability genotype combination, $5-\mathrm{HT}_{1 \mathrm{~A}} * / \mathrm{G}$ paired with $5-\mathrm{HTT}_{\text {low }}$, resulted in less efficient response to citalopram [24]. Conversely, $5-\mathrm{HT}_{1 \mathrm{~A}} \mathrm{CC}$ and $5-\mathrm{HTT}_{\text {high }}$ responded better to the SSRI fluoxetine [25]. Some studies have investigated combined effects of $5-\mathrm{HT}_{1 \mathrm{~A}}$ and 5-HTT genotypes, e.g. in major depression, mediating the influence of negative life events [65] and $5-\mathrm{HT}_{1 \mathrm{~A}} * / \mathrm{G}$ and $5-\mathrm{HTT}_{\text {low }}$ showing increased amygdala response to emotional stimuli [66], though results were not entirely consistent [67].

With respect to anxiety in FMS, there were no significant effects of serotonergic genes in HAD-A. This is consistent with the STAI showing mixed results for state and trait subscales, as the HAD covers an intermediate time frame. STAI data of all participants allowed testing for interactions between serotonin-relevant genes and group. 
Even though groups differed significantly in STAI anxiety scores, no group interaction with $5-\mathrm{HT}_{1 \mathrm{~A}}$ or 5 - HTT was observed, indicating a similar effect, regardless of baseline levels. Again, lowest anxiety scores were displayed by $5-\mathrm{HT}_{1 \mathrm{~A}} \mathrm{CC}$ in combination with $5-\mathrm{HTT}_{\text {high }}$ (Fig. 1c, d). Taking together previous literature and mechanistic function, this corroborates our findings of serotonergic gene-by-gene interactions in measures of mood.

In PPTs we found that $5-\mathrm{HT}_{1 \mathrm{~A}}$ genotypes differed depending on group, with $5-\mathrm{HT}_{1 \mathrm{~A}} \mathrm{CC}$ in $\mathrm{HC}$, i.e. a higher serotonergic tone, being less pain sensitive than G-carriers. This effect may be absent in FMS as complex modulatory processes attenuate the effect of a favourable genetic makeup. Yet, there was no effect of $5-\mathrm{HT}_{1 \mathrm{~A}}$ on pressure intensity to achieve 50/100 VAS. This is partially in line with healthy $5-\mathrm{HT}_{1 \mathrm{~A}}$ G-carriers being less sensitive at thermal pain threshold level but more sensitive at suprathreshold level, indicating a lower serotonergic tone may be associated with a "hypo-to-hyper" response [15].

Similar patterns of HC displaying more BOLD deactivation during evoked pain than FMS were observed in both rACC and thalamus but only significant in thalamus (Fig. 2a, b). BOLD deactivation could implicate a decrease in oxygen consumption and neural activity [68, 69], yet, the neurophysiological interpretation has been a matter of debate [70,71]. Some studies suggest a negative association between task-related BOLD-response and baseline GABA [72-75], including negative BOLDresponse being mediated via GABA [76]. This mechanism may lead to observed group differences, discussed for FM in [77]. However, we found no evidence that the thalamic BOLD-signal group differences during evoked pain were GABA-mediated, adding to the mixed reports on intra-regional connections between baseline GABA concentrations and task-evoked BOLD-response [72, 73, 78, 79]. Functional MRS, however, revealed an increase in glutamate/glutamine and simultaneous decrease in GABA+during painful heat stimulation [80]. Thus, a relationship between pain-relevant metabolites and pain-evoked BOLD-signal may be observed if obtained simultaneously.

Previously, we observed decreased $\mathrm{rACC}$ and thalamus activation in FMS compared to HC [29] but a stronger deactivation in $\mathrm{HC}$ compared to FMS in the current study. There are methodological differences that may explain the observed mismatch between studies. First, the stimulus differed: whereas a short (2.5 s) sharp pressure stimulus to the thumb nail was used by Jensen (2009), a cuff evoking deep-tissue pain to the leg for $5 \mathrm{~s}$ was employed here. This more ecologically valid stimulus may be less efficient in breaking through ongoing processing of perceptually similar FM pain, resulting in subtle differences compared to the baseline. Second, participants included by Jensen (2009) were more impacted by FM and subject to stricter inclusion criteria, as they participated in a pharmacological multicenter study. Current FMS were more heterogeneous, representing realistic variability in FM but making pinpointing underlying causes for discrepancies between studies more challenging. Lastly, earlier studies have found thalamic hypoperfusion in FMS [81, 82], indicating reduced blow flow may contribute to groups differences in BOLD-signal.

We found no significant group differences in GABA or glutamate concentrations in rACC or thalamus, which is consistent with previous findings [36, 83-85]. Whereas no group differences were found per se, groups' GABA concentrations differed in thalamus between 5-HTT genotypes, suggesting 5-HTT influences GABA concentration differently, depending on group affiliation. A $5-\mathrm{HT}_{1 \mathrm{~A}}$-by-5-HTT interaction was also observed in thalamic GABA concentrations, implying that the serotonergic genes elicit a combined effect. As the genotype coding for high 5-HTT expression showed significant differences in GABA concentration between groups and $5-\mathrm{HT}_{1 \mathrm{~A}}$ genotypes, it is hypothesized that higher serotonergic signalling is more impacted than less pronounced signalling by other mechanisms influencing serotonergic signalling. This would be congruent with an enhanced antidepressant treatment response in $5-\mathrm{HTT}_{\text {high }}[86-88]$ and $5-\mathrm{HT}_{1 \mathrm{~A}} \mathrm{CC}$ genotypes $[25,89]$.

One explanation could speculatively be the involvement of the transcription factor Deaf1 regulating the expression of $5-\mathrm{HT}_{1 \mathrm{~A}}$ receptors. Contrarily, Deaf1 decreases $5-\mathrm{HT}_{1 \mathrm{~A}}$ autoreceptor expression in serotonergic raphe cells but upregulates heteroreceptor expression in brain regions receiving serotonergic input $[90,91]$. The 5- $\mathrm{HT}_{1 \mathrm{~A}}$ G-allele blocks Deaf1 function, leading G-carriers to have increased $5-\mathrm{HT}_{1 \mathrm{~A}}$ autoreceptors that reduce $5-\mathrm{HT}$ firing but downregulated postsynaptic $5-\mathrm{HT}_{1 \mathrm{~A}}$ receptors, resulting in reduced $5-\mathrm{HT}$ neurotransmission. As presynaptic $5-\mathrm{HT}_{1 \mathrm{~A}}$ receptors may inhibit GABA release [92], carriers of the $5-\mathrm{HT}_{1 \mathrm{~A}}$ G-allele with reduced presynaptic $5-\mathrm{HT}_{1 \mathrm{~A}}$ receptors on GABAergic neurons would exhibit higher GABA release into the synaptic cleft. A direct link between GABA-A receptors and the somatic thalamus inhibitory system was observed in a rat model [93], suggesting pain-relevant GABA receptors mediate inhibition via the serotonergic system. Through an increase in GABA via thalamic interneuron dendrites, 5-HT can enhance GABAergic inhibitory effects, thereby modulating sensory processing in the thalamus [43].

Alterations in the transcriptional regulation could also be critical in the underlying mechanisms associated with the $5-\mathrm{HT}_{1 \mathrm{~A}}$-by-5-HTT interaction. Both polymorphisms are located within the promoter regions of each gene, resulting in altered transcription rates 
not only when the $5-\mathrm{HT}_{1 \mathrm{~A}} \mathrm{G}$-allele is present but also in association with the 5-HTTLPR S-allele (5-HTTlow). Specifically, the S-allele $\left(5-\mathrm{HTT}_{\text {low }}\right)$ initiates a reduction in transcription rate of the 5-HTT gene [94]. Taken together, the altered transcription rates affect transporter as well as receptor expression and influence the amount of extracellular serotonin that is available for postsynaptic signalling. Moreover, the 5-HTT low expression genotype has been associated with downregulation of $5-\mathrm{HT}_{1 \mathrm{~A}}$ heteroreceptors in humans [21]. Lastly, the interplay between serotonergic and GABAergic systems in the CNS is highly complex, with 5-HT intricately exerting modulatory control over glutamate- and GABA-mediated transmission that involves numerous 5-HT receptor subtypes.

\section{Limitations}

Measurement of baseline metabolites in MRS has shown mixed findings in connection with task-related fMRI. Here, functional MRS may be advantageous to understand the dynamics of glutamate/GABA in pain. Additionally, differing genotype frequencies in 5-HTT and $5-\mathrm{HT}_{1 \mathrm{~A}}$ led to differences in subgroup sizes, thus, some analyses may have been underpowered. We emphasize that replication in a larger sample is necessary. Moreover, several neurotransmitters systems are intricately linked $[7,95]$ but were not accounted for in the current study, given that the sample size is severely limited in brain imaging studies.

\section{Conclusions}

To our knowledge, this is the first report of interactions between these serotonin-relevant genes regarding mood, both in FMS (depression) and across groups (anxiety). Across groups, the 5-HT1A CC genotype in combination with the 5-HTT high expressing genotype had favourable attributes, possibly associated with producing the highest amount of postsynaptic serotonergic signalling. No significant associations were observed between the serotonergic genotypes and intensity of ongoing pain or pain sensitivity in FMS, while healthy carriers of the 5-HT1A $\mathrm{CC}$ genotype were less pain sensitive. Cerebral pain processing was not associated with serotonergic genotypes, nor with GABA or glutamate concentrations in rACC or thalamus. However, our findings provide evidence of an association between the serotonergic system and GABA levels in the thalamus, with individuals with genetically inferred high serotonergic signalling exhibiting the highest GABA concentrations.

\section{Supplementary Information}

The online version contains supplementary material available at https://doi. org/10.1186/s13041-021-00789-4.

Additional file 1: Supplementary materials and methods.

Additional file 2: Table S1. Genotype frequencies of the polymorphisms $5-\mathrm{HT}_{1 \mathrm{~A}}$ (rs6296) and the triallelic 5-HTT in fibromyalgia subjects (FMS) and healthy controls (HC). Table S2. Linear mixed model for calibrated input pressure to reach 10/100 (P10) and 50/100 VAS (P50). Table S3. ANOVAs for relative and absolute glutamate and GABA concentrations in rACC. Table S4. Absolute and relative glutamate and GABA concentrations in rACC and thalamus.

Additional file 3: Fig. S1. Group differences in anxiety scores in fibromyalgia subjects (FMS) $(n=79)$ and healthy controls $(H C)(n=40)$. FMS showed significantly higher anxiety scores measured by the STAI (State-trait anxiety inventory) in both STAI-S (state subscale) and STAI-T (trait subscale). Plotted are black circles representing estimated marginal means with the associated black vertical lines being $95 \%$ confidence intervals. In the colored boxplots, the horizontal line represents the median, the upper and lower box representing the 25th (Q1) and 75th (Q3) percentile, i.e. the interquartile range (IQR), and whiskers represent $\mathrm{Q} 1$ - and $\mathrm{Q} 3+1.5^{*} \mathrm{IQR}$. Raw data is plotted in the background.

Additional file 4: Fig. S2. Pain sensitivity measures in fibromyalgia subjects (FMS) $(n=80)$ and healthy controls $(H C)(n=40)$. A) In pressure pain thresholds (PPT) using a handheld algometer, a group-by-5- $\mathrm{HT}_{1 \mathrm{~A}}$ interaction was observed, with $5-\mathrm{HT}_{1 \mathrm{~A}} \mathrm{CC}$ in $\mathrm{HC}$ showing higher PPTs than G-carriers. This effect was not observed in FMS. B) Input pressure delivered via a rapid cuff inflation system necessary to achieve 10/100 on a visual analogue scale (VAS), P10, and 50/100 VAS, P50, differed between groups depending on pressure level. Plotted are black circles representing estimated marginal means with the associated black vertical lines being $95 \%$ confidence intervals. In the colored boxplots, the horizontal line represents the median, the upper and lower box representing the $25^{\text {th }}(\mathrm{Q} 1)$ and $75^{\text {th }}(\mathrm{Q} 3)$ percentile, i.e. the interquartile range (IQR), and whiskers represent Q1 - and Q3+1.5*IQR. Raw data is plotted in the background. $\mathrm{kPa}=$ kilopascal, $\mathrm{mmHg}=$ millimeter of mercury

\section{Acknowledgements}

The authors thank Carola Skärvinge and Anna Arvidsson at Stockholm Spine Center for excellent patient recruitment and administrative support during this project. Finally, we would like to thank the personnel at KIGene for genotyping.

\section{Authors' contributions}

Conceptualization: EK and KBJ; Funding acquisition: EK; Resources: EK, RS, MS; Patient screening: DK; Data collection: AS and JT; Formal analysis: IE and RS; Additional analysis: SF; Writing —Original draft: IE; Writing—Review and editing: all authors. All authors read and approved the finalmanuscript.

\section{Funding}

Open access funding provided by Karolinska Institute. The research leading to these results has received funding from the European Union's Horizon 2020 research and innovation programme under the Marie Skłodowska-Curie grant agreement No 764860, the European Union Seventh Framework Programme (FP7/2007-2013) under grant agreement No 602919, the Swedish Research Council (2016-01556), Stockholm County Council (LS 2018-1157), Fibromyalgiförbundet and a generous donation from Leif Lundblad and family.

\section{Availability of data and materials}

The datasets generated and analysed during the current study are available on reasonable request. 


\section{Declarations}

\section{Ethics approval and consent to participate}

All participants provided written informed consent before participation. The study was approved by the Swedish Ethical Review Authority board (permit 2014/1604-31/1) and followed the principles of the Declaration of Helsinki.

\section{Consent for publication}

Not applicable, as this manuscript does not contain any individual person's data.

\section{Competing interests}

The authors declare that they have no competing interests.

\section{Author details}

'Department of Clinical Neuroscience, Karolinska Insitutet, Nobels väg 9, 17177 Stockholm, Sweden. ${ }^{2}$ Department of Neuroradiology, Karolinska University Hospital, Stockholm, Sweden. ${ }^{3}$ Department of Oncology, Blekinge Hospital, Karlskrona, Sweden. ${ }^{4}$ Stockholm Spine Center, Löwenströmska Hospital, Upplands Väsby, Sweden. ${ }^{5}$ Department of Molecular Medicine and Surgery, Karolinska Institutet, Stockholm, Sweden. ${ }^{6}$ Center for Molecular Medicine, Karolinska University Hospital, Stockholm, Sweden. ${ }^{7}$ MRI Research Center, Karolinska University Hospital, Stockholm, Sweden. ${ }^{8}$ Department of Surgical Sciences, Uppsala University, Uppsala, Sweden.

Received: 26 February 2021 Accepted: 5 May 2021

Published online: 12 May 2021

\section{References}

1. Albert PR, Vahid-Ansari F. The 5-HT1A receptor: signaling to behavior. Biochimie. 2019:161:34-45.

2. Sharp T, Barnes NM. Central 5-HT receptors and their function; present and future. Neuropharmacology. 2020;177:108155.

3. Hornung J-P. The human raphe nuclei and the serotonergic system. J Chem Neuroanat. 2003:26:331-43.

4. Kranz GS, Kasper S, Lanzenberger R. Reward and the serotonergic system. Neuroscience. 2010;166:1023-35.

5. Jacobs BL, Azmitia EC. Structure and function of the brain serotonin system. Physiol Rev. 1992;72:165-229.

6. Smythies J, Section V. Serotonin system. Int Rev Neurobiol. 2005;64:217-68

7. Millan MJ. Descending control of pain. Prog Neurobiol. 2002;66:355-474.

8. Hensler JG. Chapter 3.5-Serotonin in mood and emotion. In: Müller CP, Jacobs BL, editors. Handbook of the behavioral neurobiology of serotonin. Elsevier; 2010. p. 367-78. http://www.sciencedirect.com/science/ article/pii/S1569733910700904

9. O'Leary OF, Cryan JF. Chapter 4.13-The behavioral genetics of serotonin: relevance to anxiety and depression. In: Müller CP, Jacobs BL, editors. Handbook of the behavioral neurobiology of serotonin. Elsevier; 2010. p. 749-89.

10. Chen Q, Heinricher MM. Descending control mechanisms and chronic pain. Curr Rheumatol Rep. 2019;21:13.

11. Sommer C. Chapter 3.11—Serotonin in pain and pain control. In: Müller $C P$, Jacobs BL, editors. Handbook of the behavioral neurobiology of serotonin. Elsevier; 2010. p. 457-71. http://www.sciencedirect.com/scien ce/article/pii/S1569733910700965

12. Lesch KP, Bengel D, Heils A, Sabol SZ, Greenberg BD, Petri S, et al. Association of anxiety-related traits with a polymorphism in the serotonin transporter gene regulatory region. Science. 1996:274:1527-31.

13. Garcia-Garcia AL, Newman-Tancredi A, Leonardo ED. 5-HT(1A) receptors in mood and anxiety: recent insights into autoreceptor versus heteroreceptor function. Psychopharmacology. 2014;231:623-36.

14. Lindstedt F, Berrebi J, Greayer E, Lonsdorf TB, Schalling M, Ingvar M, et al. Conditioned pain modulation is associated with common polymorphisms in the serotonin transporter gene. PLOS ONE. 2011;6:e18252.

15. Lindstedt $F$, Karshikoff B, Schalling M, Höglund CO, Ingvar M, Lekander $M$, et al. Serotonin-1A receptor polymorphism (rs6295) associated with thermal pain perception. PLoS ONE. 2012:7:e43221.
16. Treister R, Pud D, Ebstein RP, Laiba E, RazY Gershon E, et al. Association between polymorphisms in serotonin and dopamine-related genes and endogenous pain modulation. J Pain. 2011:12:875-83.

17. Parsey RV, Ogden RT, Miller JM, Tin A, Hesselgrave N, Goldstein E, et al. Higher serotonin $1 \mathrm{~A}$ binding in a second major depression cohort: modeling and reference region considerations. Biol Psychiatry. 2010;68:170-8.

18. Hesselgrave N, Parsey RV. Imaging the serotonin 1A receptor using [11C] WAY100635 in healthy controls and major depression. Philos Trans R Soc Lond B Biol Sci. 2013;368:20120004.

19. Kautzky A, James GM, Philippe C, Baldinger-Melich P, Kraus C, Kranz GS, et al. The influence of the rs6295 gene polymorphism on serotonin-1A receptor distribution investigated with PET in patients with major depression applying machine learning. Transl Psychiatry. 2017;7:e1150.

20. Li Q, Wichems C, Heils A, Van De Kar LD, Lesch KP, Murphy DL. Reduction of 5-hydroxytryptamine (5-HT)(1A)-mediated temperature and neuroendocrine responses and 5-HT(1 A) binding sites in 5-HT transporter knockout mice. J Pharmacol Exp Ther. 1999;291:999-1007.

21. David SP, Murthy NV, Rabiner EA, Munafó MR, Johnstone EC, Jacob R, et al. A functional genetic variation of the serotonin (5-HT) transporter affects 5-HT1A receptor binding in humans. J Neurosci. 2005:25:2586-90.

22. Christian BT, Wooten DW, Hillmer AT, Tudorascu DL, Converse AK, Moore CF, et al. Serotonin transporter genotype affects serotonin 5-HT1A binding in primates. J Neurosci. 2013;33:2512-6.

23. Tour J, Löfgren M, Mannerkorpi K, Gerdle B, Larsson A, Palstam A, et al. Gene-to-gene interactions regulate endogenous pain modulation in fibromyalgia patients and healthy controls-antagonistic effects between opioid and serotonin-related genes. Pain. 2017;158:1194-203.

24. Arias B, Catalán R, Gastó C, Gutiérrez B, Fañanás L. Evidence for a combined genetic effect of the $5-\mathrm{HT}(1 \mathrm{~A})$ receptor and serotonin transporter genes in the clinical outcome of major depressive patients treated with citalopram. J Psychopharmacol Oxf Engl. 2005;19:166-72.

25. Hong C-J, Chen T-J, Yu YWY, Tsai S-J. Response to fluoxetine and serotonin 1 A receptor (C-1019G) polymorphism in Taiwan Chinese major depressive disorder. Pharmacogenomics J. 2006;6:27-33.

26. Pettitt A. Genetic variations in the serotonergic system mediate a combined, weakened response to SSRI treatment: a proposed model. eNeuro. 2015;2:1-12.

27. Kosek E, Hansson P. Modulatory influence on somatosensory perception from vibration and heterotopic noxious conditioning stimulation (HNCS) in fibromyalgia patients and healthy subjects. Pain. 1997;70:41-51.

28. Julien N, Goffaux P, Arsenault P, Marchand S. Widespread pain in fibromyalgia is related to a deficit of endogenous pain inhibition. Pain. 2005; 114:295-302.

29. Jensen KB, Kosek E, Petzke F, Carville S, Fransson P, Marcus H, et al. Evidence of dysfunctional pain inhibition in fibromyalgia reflected in $\mathrm{rACC}$ during provoked pain. Pain. 2009;144:95-100.

30. Jensen KB, Loitoile R, Kosek E, Petzke F, Carville S, Fransson P, et al. Patients with fibromyalgia display less functional connectivity in the brain's pain inhibitory network. Mol Pain. 2012:8:32.

31. Russell IJ, Vaeroy H, Javors M, Nyberg F. Cerebrospinal fluid biogenic amine metabolites in fibromyalgia/fibrositis syndrome and rheumatoid arthritis. Arthritis Rheum. 1992;35:550-6.

32. Ablin JN, Buskila D. Update on the genetics of the fibromyal gia syndrome. Best Pract Res Clin Rheumatol. 2015;29:20-8.

33. Fields H. State-dependent opioid control of pain. Nat Rev Neurosci. 2004;5:565-75

34. Yohn CN, Gergues MM, Samuels BA. The role of 5-HT receptors in depression. Mol Brain. 2017:10:28

35. Goudet C, Magnaghi V, Landry M, Nagy F, Gereau RW IV, Pin J-P. Metabotropic receptors for glutamate and GABA in pain. Brain Res Rev. 2009;60:43-56

36. Feraco P, Bacci A, Pedrabissi F, Passamonti L, Zampogna G, Pedrabissi $F$, et al. Metabolic abnormalities in pain-processing regions of patients with fibromyalgia: a 3T MR spectroscopy study. AJNR Am J Neuroradiol. 2011;32:1585-90

37. Foerster BR, Petrou M, Edden RAE, Sundgren PC, Schmidt-Wilcke T, Lowe $\mathrm{SE}$, et al. Reduced insular $\gamma$-aminobutyric acid in fibromyalgia. Arthritis Rheum. 2012;64:579-83.

38. Pomares FB, Roy S, Funck T, Feier NA, Thiel A, Fitzcharles M-A, et al. Upregulation of cortical GABAA receptor concentration in fibromyalgia. Pain 2020:161:74-82 
39. Möhler $\mathrm{H}$. The GABA system in anxiety and depression and its therapeutic potential. Neuropharmacology. 2012;62:42-53.

40. Niciu MJ, lonescu DF, Richards EM, Zarate CA. Glutamate and its receptors in the pathophysiology and treatment of major depressive disorder. J Neural Transm. 2014;121:907-24.

41. Enna SJ, McCarson KE. The role of GABA in the mediation and perception of pain. Adv Pharmacol. 2006;54:1-27.

42. Ciranna L. Serotonin as a modulator of glutamate- and GABA-mediated neurotransmission: implications in physiological functions and in pathology. Curr Neuropharmacol. 2006:4:101-14.

43. Munsch T, Freichel M, Flockerzi V, Pape H-C. Contribution of transient receptor potential channels to the control of GABA release from dendrites. Proc Natl Acad Sci U S A. 2003;100:16065-70.

44. Albrecht DS, Forsberg A, Sandström A, Bergan C, Kadetoff D, Protsenko E, et al. Brain glial activation in fibromyalgia - a multi-site positron emission tomography investigation. Brain Behav Immun. 2019;75:72-83.

45. Sandström A, Ellerbrock I, Tour J, Kadetoff D, Jensen KB, Kosek E. Neural correlates of conditioned pain responses in fibromyalgia subjects indicate preferential formation of new pain associations rather than extinction of irrelevant ones. Pain. 2020;161:2079-88.

46. Ellerbrock I, Sandström A, Tour J, Kadetoff D, Schalling M, Jensen KB, et al. Polymorphisms of the $\mu$-opioid receptor gene influence cerebral pain processing in fibromyalgia. Eur J Pain. 2021;25:398-414.

47. Sullivan MJL, Bishop SR, Pivik J. The pain catastrophizing scale: development and validation. Psychol Assess. 1995;7:524-32.

48. Beck AT, Ward CH, Mendelson M, Mock J, Erbaugh J. An inventory for measuring depression. Arch Gen Psychiatry. 1961:4:561-71.

49. Zigmond AS, Snaith RP. The hospital anxiety and depression scale. Acta Psychiatr Scand. 1983;67:361-70

50. Spielberger C, Gorsuch R, Lushene R, Vagg P, Jacobs G. Manual for the state-trait anxiety inventory. Palo Alto, CA: Consulting Psychologists Press, Inc.; 1983.

51. Burckhardt CS, Clark SR, Bennett RM. The fibromyalgia impact questionnaire: development and validation. J Rheumatol. 1991;18:728-33.

52. Kosek E, Ekholm J, Nordemar R. A comparison of pressure pain thresholds in different tissues and body regions. Long-term reliability of pressure algometry in healthy volunteers. Scand J Rehabil Med. 1993;25:117-24.

53. Govindaraju V, Young K, Maudsley AA. Proton NMR chemical shifts and coupling constants for brain metabolites. NMR Biomed. 2000;13:129-53.

54. Govind V, Young K, Maudsley AA. Corrigendum: proton NMR chemical shifts and coupling constants for brain metabolites. Govindaraju V, Young K, Maudsley AA, NMR Biomed. 2000; 13: 129-153. NMR Biomed. 2015;28:923-4

55. Power JD, Barnes KA, Snyder AZ, Schlaggar BL, Petersen SE. Spurious but systematic correlations in functional connectivity MRI networks arise from subject motion. Neuroimage. 2012;59:2142-54.

56. Wendland JR, Martin BJ, Kruse MR, Lesch K-P, Murphy DL. Simultaneous genotyping of four functional loci of human SLC6A4, with a reappraisal of 5-HTTLPR and rs25531. Mol Psychiatry. 2006;11:224-6.

57. R Core Team. R: A language and environment for statistical computing. Vienna, Austria: R Foundation for Statistical Computing; 2020. https:// www.R-project.org/.

58. Singmann $\mathrm{H}$, Bolker $\mathrm{B}$, Westfall J, Aust F, Ben-Shachar MS. afex: analysis of factorial experiments. R package version 0.28-0. 2020. https://CRAN.Rproject.org/package $=$ afex.

59. Lenth R. emmeans: estimated marginal means, aka least-squares means. R package version 1.5.2-1.2020. https://CRAN.R-project.org/package $=$ emmeans.

60. Holm S. A simple sequentially rejective multiple test procedure. Scand J Stat. 1979;6:65-70.

61. Wolfe F, Russell IJ, Vipraio G, Ross K, Anderson J. Serotonin levels, pain threshold, and fibromyalgia symptoms in the general population. J Rheumatol. 1997;24:555-9.

62. Lemonde S, Du L, Bakish D, Hrdina P, Albert PR. Association of the C(-1019)G 5-HT1A functional promoter polymorphism with antidepressant response. Int J Neuropsychopharmacol. 2004:7:501-6.

63. Yu YW-Y, Tsai S-J, Liou Y-J, Hong C-J, Chen T-J. Association study of two serotonin $1 \mathrm{~A}$ receptor gene polymorphisms and fluoxetine treatment response in Chinese major depressive disorders. Eur Neuropsychopharmacol. 2006;16:498-503.
64. Hooten WM, Townsend CO, Sletten CD. The triallelic serotonin transporter gene polymorphism is associated with depressive symptoms in adults with chronic pain. J Pain Res. 2017;10:1071-8.

65. Zhang $K, X u Q, X u Y$, , Yang $H$, Luo J, Sun Y, et al. The combined effects of the 5-HTTLPR and 5-HTR1A genes modulates the relationship between negative life events and major depressive disorder in a Chinese population. J Affect Disord. 2009:114:224-31.

66. Dannlowski U, Ohrmann P, Bauer J, Kugel H, Baune BT, Hohoff C, et al. Serotonergic genes modulate amygdala activity in major depression. Genes Brain Behav. 2007;6:672-6.

67. Basu A, Chadda RK, Sood M, Kaur H, Kukreti R. A preliminary association study between serotonin transporter (5-HTTLPR), receptor polymorphisms (5-HTR1A, 5-HTR2A) and depression symptom-clusters in a north Indian population suffering from Major Depressive Disorder (MDD). Asian J Psychiatry. 2019:43:184-8.

68. Shmuel A, Yacoub E, Pfeuffer J, Van de Moortele PF, Adriany G, Hu X, et al. Sustained negative BOLD, blood flow and oxygen consumption response and its coupling to the positive response in the human brain. Neuron. 2002;36:1195-210.

69. Huber L, Goense J, Kennerley AJ, Ivanov D, Krieger SN, Lepsien J, et al. Investigation of the neurovascular coupling in positive and negative BOLD responses in human brain at 7 T. Neuroimage. 2014;97:349-62.

70. Wade AR. The negative BOLD signal unmasked. Neuron. 2002;36:993-5.

71. Mullinger KJ, Mayhew SD, Bagshaw AP, Bowtell R, Francis ST. Evidence that the negative $B O L D$ response is neuronal in origin: a simultaneous EEG-BOLD-CBF study in humans. Neuroimage. 2014;94:263-74.

72. Donahue MJ, Near J, Blicher JU, Jezzard P. Baseline GABA concentration and fMRI response. Neuroimage. 2010;53:392-8.

73. Stagg CJ, Bachtiar V, Johansen-Berg H. The role of GABA in human motor learning. Curr Biol CB. 2011;21:480-4.

74. Muthukumaraswamy SD, Evans CJ, Edden RAE, Wise RG, Singh KD. Individual variability in the shape and amplitude of the BOLD-HRF correlates with endogenous GABAergic inhibition. Hum Brain Mapp. 2012;33:455-65.

75. Violante IR, Ribeiro MJ, Edden RAE, Guimarães P, Bernardino I, Rebola J, et al. GABA deficit in the visual cortex of patients with neurofibromatosis type 1: genotype-phenotype correlations and functional impact. Brain Oxford Academic. 2013;136:918-25.

76. Northoff G, Walter M, Schulte RF, Beck J, Dydak U, Henning A, et al. GABA concentrations in the human anterior cingulate cortex predict negative BOLD responses in fMRI. Nat Neurosci. 2007;10:1515-7.

77. Napadow V, Harris RE. What has functional connectivity and chemical neuroimaging in fibromyalgia taught us about the mechanisms and management of 'centralized'pain? Arthritis Res Ther. 2014;16:425.

78. Muthukumaraswamy SD, Edden RAE, Jones DK, Swettenham JB, Singh $\mathrm{KD}$. Resting GABA concentration predicts peak gamma frequency and fMRI amplitude in response to visual stimulation in humans. Proc Natl Acad Sci. 2009;106:8356-61.

79. Harris AD, Puts NAJ, Anderson BA, Yantis S, Pekar JJ, Barker PB, et al. Multiregional investigation of the relationship between functional MRI blood oxygenation level dependent (BOLD) activation and GABA concentration. PLOS ONE. 2015;10:e0117531.

80. Cleve M, Gussew A, Reichenbach JR. In vivo detection of acute paininduced changes of GABA+ and Glx in the human brain by using functional 1H MEGA-PRESS MR spectroscopy. Neuroimage. 2015;105:67-75.

81. Mountz JM, Bradley LA, Modell JG, Alexander RW, Triana-Alexander M, Aaron LA, et al. Fibromyalgia in women. Abnormalities of regional cerebral blood flow in the thalamus and the caudate nucleus are associated with low pain threshold levels. Arthritis Rheum. 1995;38:926-38.

82. Kwiatek R, Barnden L, Tedman R, Jarrett R, Chew J, Rowe C, et al. Regional cerebral blood flow in fibromyalgia: single-photon-emission computed tomography evidence of reduction in the pontine tegmentum and thalami. Arthritis Rheum. 2000;43:2823-33.

83. Fayed N, Garcia-Campayo J, Magallón R, Andrés-Bergareche H, Luciano $J V$, Andres E, et al. Localized 1H-NMR spectroscopy in patients with fibromyalgia: a controlled study of changes in cerebral glutamate/glutamine, inositol, choline, and N-acetylaspartate. Arthritis Res Ther. 2010;12:R134.

84. Valdés M, Collado A, Bargalló N, Vázquez M, Rami L, Gómez E, et al. Increased glutamate/glutamine compounds in the brains of patients with fibromyalgia: a magnetic resonance spectroscopy study. Arthritis Rheum. 2010;62:1829-36. 
85. Peek AL, RebbeckT, Puts NA, Watson J, Aguila M-ER, Leaver AM. Brain GABA and glutamate levels across pain conditions: a systematic literature review and meta-analysis of $1 \mathrm{H}-\mathrm{MRS}$ studies using the MRS-Q quality assessment tool. Neuroimage. 2020;210:116532.

86. Smeraldi E, Zanardi R, Benedetti F, Di Bella D, Perez J, Catalano M. Polymorphism within the promoter of the serotonin transporter gene and antidepressant efficacy of fluvoxamine. Mol Psychiatry. 1998;3:508-11.

87. Serretti A, Kato M, De Ronchi D, Kinoshita T. Meta-analysis of serotonin transporter gene promoter polymorphism (5-HTTLPR) association with selective serotonin reuptake inhibitor efficacy in depressed patients. Mol Psychiatry. 2007;12:247-57.

88. Porcelli S, Fabbri C, Serretti A. Meta-analysis of serotonin transporter gene promoter polymorphism (5-HTTLPR) association with antidepressant efficacy. Eur Neuropsychopharmacol. 2012;22:239-58.

89. Malaguti A, Rossini D, Lucca A, Magri L, Lorenzi C, Pirovano A, et al. Role of COMT, 5-HT1A, and SERT genetic polymorphisms on antidepressant response to transcranial magnetic stimulation. Depress Anxiety. 2011;28:568-73.

90. Czesak M, Lemonde S, Peterson EA, Rogaeva A, Albert PR. Cell-specific repressor or enhancer activities of Deaf- 1 at a serotonin $1 \mathrm{~A}$ receptor gene polymorphism. J Neurosci. 2006;26:1864-71.

91. Czesak M, Le François B, Millar AM, Deria M, Daigle M, Visvader JE, et al. Increased serotonin-1A (5-HT1A) autoreceptor expression and reduced raphe serotonin levels in deformed epidermal autoregulatory factor-1 (Deaf-1) gene knock-out mice. J Biol Chem. 2012;287:6615-27.

92. Lee KS, Han TH, Jo JY, Kang G, Lee SY, Ryu PD, et al. Serotonin inhibits GABA synaptic transmission in presympathetic paraventricular nucleus neurons. Neurosci Lett. 2008;439:138-42.

93. Roberts WA, Eaton SA, Salt TE. Widely distributed GABA-mediated afferent inhibition processes within the ventrobasal thalamus of rat and their possible relevance to pathological pain states and somatotopic plasticity. Exp Brain Res. 1992;89:363-72.

94. Maier W, Zobel A. Contribution of allelic variations to the phenotype of response to antidepressants and antipsychotics. Eur Arch Psychiatry Clin Neurosci. 2008;258:12-20.

95. Adell A, Bortolozzi A, Díaz-Mataix L, Santana N, Celada P, Artigas F. Chapter 2.8-Serotonin interaction with other transmitter systems. In: Müller CP, Jacobs BL, editors. Handbook of the behavioral neurobiology of serotonin. Elsevier: Amsterdam; 2010. p. 259-76.

\section{Publisher's Note}

Springer Nature remains neutral with regard to jurisdictional claims in published maps and institutional affiliations.
Ready to submit your research? Choose BMC and benefit from:

- fast, convenient online submission

- thorough peer review by experienced researchers in your field

- rapid publication on acceptance

- support for research data, including large and complex data types

- gold Open Access which fosters wider collaboration and increased citations

- maximum visibility for your research: over 100M website views per year

At BMC, research is always in progress.

Learn more biomedcentral.com/submissions 